\title{
ESTIMATION OF SENSIBLE AND LATENT HEAT FLUX FROM NATURAL SPARSE VEGETATION SURFACES USING SURFACE RENEWAL
}

N. Zapata ${ }^{1}$, A. Martínez-Cob ${ }^{1,2}$

${ }^{1}$ Departamento de Genética y Producción Vegetal (EEAD)

Laboratorio Asociado de Agronomía y Medio Ambiente (DGA-CSIC)

Apartado 202

50080 Zaragoza (Spain)

Phone: 34-976716086

Fax: 34-976716145

${ }^{2}$ To whom the correspondence should be addressed

E-mail: macoan@eead.csic.es 


\section{ABSTRACT}

This paper reports a study undertaken to evaluate the feasibility of the surface renewal method to accurately estimate long-term evaporation from the playa and margins of an endorreic salty lagoon (Gallocanta lagoon, Spain) under semiarid conditions. High-frequency temperature readings were taken for two time lags $(r)$ and three measurement heights $(z)$ in order to get surface renewal sensible heat flux $\left(H_{S R}\right)$ values. These values were compared against eddy covariance sensible heat flux $\left(H_{E C}\right)$ values for a calibration period (25 to 30 July 2000). Error analysis statistics (index of agreement, $I A$; root mean square error, RMSE; and systematic mean square error, $M S E_{S}$ ) showed that the agreement between $H_{S R}$ and $H_{E C}$ improved as measurement height decreased and time lag increased. Calibration factors $\alpha$ were obtained for all analyzed cases. The best results were obtained for the $z=0.9 \mathrm{~m}(r=$ 0.75 s) case for which $\alpha=1.0$ was observed. In this case, uncertainty was about 10 $\%$ in terms of relative error $(R E)$. Latent heat flux values were obtained by solving the energy balance equation for both the surface renewal $\left(L E_{S R}\right)$ and the eddy covariance ( $\left.L E_{E C}\right)$ methods, using $H_{S R}$ and $H_{E C}$, respectively, and measurements of net radiation and soil heat flux. For the calibration period, error analysis statistics for $L E_{S R}$ were quite similar to those for $H_{S R}$, although errors were mostly at random. $L E_{S R}$ uncertainty was less than $9 \%$. Calibration factors were applied for a validation data subset (30 July to 4 August 2000) for which meteorological conditions were somewhat different (higher temperatures and wind speed and lower solar and net radiation). Error analysis statistics for both $H_{S R}$ and $L E_{S R}$ were quite good for all cases showing the goodness of the calibration factors. Nevertheless, the results obtained for the $z=0.9 \mathrm{~m}(r=0.75 \mathrm{~s})$ case were still the best ones. 


\section{Keywords}

Evapotranspiration

Surface renewal

Natural vegetation

Sensible heat flux

Eddy covariance

\section{INTRODUCTION}

Preserving natural humid areas, such as lagoons and natural ponds, in semiarid regions is paramount because of their impact on the climate, the flora and fauna, and the agriculture of those regions. For such purposes, a detailed and accurate knowledge of the hydrology of those areas becomes critical. In many instances, these areas are endorreic. Therefore, the water level of these reservoirs is highly dependent upon precipitation, falling directly over the area or running into from adjacent areas, and evaporation of both free and soil water and transpiration of phreatophytes around the margins of the reservoir. In some cases, man activities also affect that balance by extracting water from water table for irrigation. These endorreic areas commonly show high salt concentrations in both the water reservoir itself and the soils of the surrounding margins and moist playa.

These areas are characterized for sparse vegetation with high proportions of bare soil. In general terms, little attention has been paid to continuous monitoring of water losses in this sparse-vegetation environments. Allison and Barnes (1985) estimated evaporation from the floor of Lake Frome, a normally "dry" salt lake in 
northern South Australia. Malek et al. (1990; 1997) have measured evapotranspiration in the heterogeneous vegetation of a desert valley in Utah (United States). Within the Sahel area (Niger), Culf et al. (1993) performed energy and water budgets of a patterned woodland, while Goutorbe et al. (1997) performed a detailed hydrometeorological study. Lapitan and Parton (1996) studied evapotranspiration of the semiarid shortgrass steppes of Colorado (United States). There has been other studies focused only on bare soil evaporation in sparse vegetation areas (Jacobs and Verhoef, 1997; Qiu et al., 1999; Wythers et al., 1999, among others).

Micrometeorological measurements and the energy balance equation are adequate for these type of studies. The eddy covariance method is the only micrometeorological method that provide direct accurate measurements of latent heat flux. However, eddy covariance systems may underestimate latent heat flux due to the physical separation of sensors (Foken and Wichura, 1996; Kristensen et al., 1997; Villalobos, 1997). Furthermore, eddy covariance measurements can be compromised by low wind speeds and by mounting or sensor head distortions (Paw U et al., 1995; Foken and Wichura, 1996). Additionally, their equipment is relatively expensive and requires a continuous maintenance and monitoring for accurate measurements. In situations where measurements must be taken at remote places, these limitations can be paramount, if continuous long-term measurements are needed and maintenance costs must be highly reduced.

Alternatively, other micrometeorological methods can be used to determine sensible heat flux, using several approaches, and, by solving the energy balance equation, to estimate latent heat flux. In general, these methods, such as the Bowen ratio method, have a sound theoretical basis, have been thoroughly evaluated and 
are highly accurate. Within these methods, Paw U et al. (1995) have suggested to estimate scalar fluxes using scalar signals without high frequency velocity data, thus reducing the number of instruments required and the cost as compared to the Bowen ratio method or other approaches. Subsequently, Paw U and Brunet (1991) and Paw U et al. (1995) have proposed a new high-frequency sampling method for estimating scalar fluxes, the surface renewal (SR) method. This method does not require temperature profiles and wind speed data as required for other temperature variability methods (De Bruin et al., 1993). The SR method has been tested with air temperature data recorded for different crop canopies and provided good estimates of sensible heat flux $(H)$ regardless of the stability conditions and the flux direction (Paw U et al., 1995; Snyder et al., 1996; Spano et al., 1997; Spano et al., 2000). However, Snyder et al. (1996) and Spano et al. (1997) have indicated the SR method may require that an appropriate calibration factor be obtained. Chen et al. (1997) have indicated that that calibration factor may depend on the surface being measured.

This paper presents a study performed in the playa and margins of an endorreic lagoon characterized by short, sparse vegetation where bare soil is predominant. The SR method has not been tested yet over this type of surfaces. Sensible heat flux $(H)$ values obtained with this method were compared against independent $H$ measurements obtained with an eddy covariance system. The main goal of this work was the evaluation, and eventual calibration, of the surface renewal method as a reasonably accurate, low-cost and long-term procedure to obtain accurate estimates of the evaporation of water in natural areas of short, sparse vegetation. 


\section{MATERIAL AND METHODS}

\subsection{Theory of the surface renewal method}

Traces of high-frequency temperature data show ramp-like structures resulting from turbulent coherent structures (Gao et al., 1989; Shaw et al., 1989; Paw U et al., 1992). The coherent structure theory assumes that an air parcel sweeps from above to the surface. The transfers between the air and the canopy elements lead to heating or cooling of the air while is at the surface. Then, the air parcel ejects from the surface and is replaced by a new air parcel sweeping to the surface. Because these fluctuations are coherent, ramps are observed when high-frequency temperature measurements are taken at a point at or above the canopy top. Two parameters characterize these mean temperature ramps for stable and unstable atmospheric conditions (Paw $U$ and Brunet, 1991): the amplitude (a) and the inverse ramp frequency $(I+s)$. The mean values of these two parameters during a time interval can be used to estimate $H$ over several crop canopies (Paw $U$ and Brunet, 1991; Paw U et al., 1995; Snyder et al., 1996) using surface renewal (SR) analysis.

Following Paw $U$ and Brunet (1991) and Paw $U$ et al. (1995), $H$ can be determined from the change in heat content with time $(d T / d t)$ as follows:

$$
H=\rho c_{p} \frac{d T}{d t} \frac{V}{A}
$$

where $\rho$ is the air density, $c_{p}$ is specific heat of air, and V/A is the volume of air per unit area under the canopy height. It is assumed that $\mathrm{dT} / \mathrm{dt} \approx \partial \mathrm{T} / \partial \mathrm{t}$, the air parcel height is equal to the canopy height $\left(z_{c}\right)$ (then $V / A=z_{c}$ ) and internal advection is negligible (Paw U and Brunet, 1991; Paw U et al., 1995). In SR analysis, equation (1) 
is further simplified such that average $H$ for a given time interval is obtained from the following expression (Paw U et al., 1995):

$$
H=\alpha \rho c_{p} \frac{a}{l+s} z_{c}
$$

The weighting factor $\alpha$ accounts for the spatially averaged (vertical) air temperature derivative from the bottom to the top of the air parcel. Paw $U$ et al. (1995) indicated that $\alpha \approx 0.5$ when high-frequency air temperature data are measured at the top canopy height $\left(z_{c}\right)$ for tall-canopy crops. According to these authors, the change in heating with height is assumed to be linear from the ground to the top of the canopy, and the air heating near the ground is assumed to be negligible. Thus, heating of the air parcel volume should be about half of the heating measured at the canopy top. However, Snyder et al. (1996) showed poor results when using $\alpha=0.5$ for short-canopy crops such as grass and wheat. In these cases, Snyder et al. (1996) suggested a value of $\alpha=1.0$ as long as measurements are taken well above the canopy top, and assuming that heat flux occurs instantaneously and adiabatically during the sweep and ejection phase, and the air parcel is heated approximately to the same temperature throughout. In this case, $z_{c}$ can be substituted in equation (2) by $z$, the sensor measurement height.

$$
H=\rho c_{p} \frac{a}{I+s} z
$$

Nevertheless, Snyder et al. (1996), Spano et al. (1997) and Duce et al. (1997) have reported that $\alpha$ changes with measurement height and recommended obtaining appropriate $\alpha$ values for short-canopy crops by comparison against independent measurements of $H$. 
Several solutions have been proposed to estimate the mean ramp characteristics (Paw U and Brunet, 1991; Paw U et al., 1995; Chen et al., 1997). Snyder et al. (1996) and Spano et al. (1997) suggested the Van Atta (1977) approach to estimate the mean ramp characteristics to be used in equation (2). Following Van Atta (1977), high-frequency temperature measurements are used to determine structure functions $S^{p}(r)$ according to the expression:

$$
S^{p}(r)=\frac{1}{m-j} \sum_{i=1+j}^{m}\left(T_{i}-T_{i-j}\right)^{p}
$$

where $m$ is the number of data points measured at a frequency $f$ (in $\mathrm{Hz}$ ) within a $t$ minute interval, $p$ is the power of the function $(p=2,3$ and 5$), j$ is a sample lag between data points corresponding to a time lag $r=j / f$, and $T_{i}$ is the $i^{\text {th }}$ temperature sample.

The mean amplitude a for the $t$-minute interval is estimated by solving the following equation for the real roots:

$$
a^{3}+\left[10 S^{2}(r)-\frac{S^{5}(r)}{S^{3}(r)}\right] a+10 S^{3}(r)=0
$$

And finally, the inverse ramp frequency $(I+S)$ is calculated by the expression:

$$
I+S=-\frac{a^{3} r}{S^{3}(r)}
$$

\subsection{Experimental setup}

This research was carried out in the margins of Gallocanta lagoon (40 59'09" $\mathrm{N}$ latitude, $1^{\circ} 30^{\prime} 17^{\prime \prime} \mathrm{W}$ longitude, altitude $\left.1000 \mathrm{~m}\right)$. The average annual precipitation 
of the Gallocanta basin is about $435 \mathrm{~mm}$. The size of the lagoon (and that of its playa) shows a high variability among years.

A weather station was installed in a $10 \mathrm{~m} \times 5 \mathrm{~m}$ spot in the northern area of the lagoon, surrounded by a 2-m wire fence (Figure 1 ). In this site, the lagoon bed is about $50 \mathrm{~m}$ at each side of the weather station. Natural vegetation with a high proportion of bare soil is predominant. In general, plants were only a few $\mathrm{cm}$ high although there were some spots with 0.4-0.5 $\mathrm{m}$ high plants.

During the measurement period (25 July to 4 August 2000), the station was equipped with three dataloggers (CR10X Campbell Scientific), hereafter referred to as Galloca 1, Galloca 2 and Galloca 3, respectively. Galloca 1 datalogger was used for standard meteorological measurements: air temperature and relative humidity, wind speed and direction at $2.0 \mathrm{~m}$ above ground, solar global and net radiation, and soil heat flux. An eddy covariance system (1-D sonic anemometer and a fine wire thermocouple attached to the anemometer) was installed at $1.4 \mathrm{~m}$ above ground and connected to Galloca 2 datalogger to obtain an independent measure of sensible heat flux. Eddy covariance sensors were monitored at $8 \mathrm{~Hz}$ frequency. Covariances between vertical wind and air temperature fluctuations were recorded every 30 minutes. 30-min eddy covariance sensible heat flux $\left(H_{E C}\right)$ values were obtained from these covariances as explained by Monteith and Unsworth (1990) and Foken and Wichura (1996).

Three fine wire thermocouples TCBR-3 were installed, one connected to Galloca 2 datalogger and the other two connected to Galloca 3 datalogger. Air temperature was monitored with the TCBR-3 thermocouples at $8 \mathrm{~Hz}$ (datalogger Galloca 2) and $5.3 \mathrm{~Hz}$ (datalogger Galloca 3) frequencies. 30 -min sums of the $2^{\text {nd }}, 3^{\text {rd }}$ 
and $5^{\text {th }}$ powers of the differences between the $i^{\text {th }}$ and the $(i-j)^{\text {th }}$ temperature samples were recorded to apply equation (4).

Snyder et al. (1996), Spano et al. (1997) and Duce et al. (1997) have reported that the weighting factor $\alpha$ used in equation (2) varies according to the measurement height and the time lag used to estimate the mean ramp characteristics using equations (4) to (6). Then, three heights above ground ( $z$ ) were used in this research: 1.4 (datalogger Galloca 2), 1.1 and 0.9 m (datalogger Galloca 3). Likewise, two time lags were used for each measurement height: a) longer time lag, $0.50 \mathrm{~s}(z=1.4 \mathrm{~m})$ and $0.75 \mathrm{~s}(z=1.1$ and $0.9 \mathrm{~m}) ; \mathrm{b})$ shorter time lag, $0.25 \mathrm{~s}(z=1.4 \mathrm{~m})$ and $0.375 \mathrm{~s}(z$ $=1.1$ and $0.9 \mathrm{~m}$ ). Therefore, a total of six sets of 30 -min surface renewal sensible heat flux $\left(H_{S R}\right)$ values were estimated using the linearized solution of Van Atta (1977) as described in equations (3) through (6). This solution requires the time lag $r$ must be much less than I+s (Van Atta, 1977). Thus, ramp characteristic calculations were only kept when l+s was greater than $5 \times r$ (Snyder, personal communication). An iterative procedure, the Newton method, described in most numerical analysis textbooks, was used to find the real roots of equation (5).

The energy balance equation was solved to obtain latent heat flux values using measured net radiation and soil heat flux (datalogger Galloca 1), and measured $H_{E C}$ or estimated $H_{S R}$ values. Thus, a single data set of 30-min values of eddy covariance $\left(L E_{E C}\right)$ and six data sets of surface renewal $\left(L E_{S R}\right)$ latent heat flux were obtained.

The whole data set was divided in two subsets: a) calibration data subset, from 25 July (12:00 Greenwich Meridian Time, GMT) to 30 July (11:30 GMT); b) validation data subset, from 30 July (12:00 GMT) to 4 August (10:30 GMT). The 
calibration data subset was used to derive a $\alpha$ value for each combination of measurement height and time lag by simple linear regression forced through the origin. For this regression, $H_{E C}$ was used as the dependent variable and $H_{S R}$ as the independent one. In this way, the regression slope was the $\alpha$ value looked for. The different $\alpha$ values were used to correct $H$ (and thus $L E$ ) values obtained for the validation data set. Error analysis was performed for both calibration and validation $H$ and $L E$ data subsets. The following statistics were computed as described by Willmott (1982): a) index of agreement $(I A)$, varying from 0 (not agreement at all) to 1 (complete agreement); b) root mean square error (RMSE); and c) systematic mean square error $\left(M S E_{s}\right)$. An additional statistics, the relative error (RE) was also computed as the ratio between RMSE and the difference between maximum and minimum values of the dependent variable ( $H_{E C}$ or $\left.L E_{E C}\right)$ (Duce et al., 1997). The IA was computed following Willmott (1982) as:

$$
I A=1-\frac{\sum_{i=1}^{n}\left(y_{i}-x_{i}\right)^{2}}{\sum_{i=1}^{n}\left(\left|y_{i}-\bar{x}\right|+\left|x_{i}-\bar{x}\right|\right)^{2}}
$$

where $y_{i}$ is the value of the dependent variable $\left(H_{E C}\right.$ or $\left.L E_{E C}\right)$ for half hour $i ; x_{i}$ is the value of the independent variable $\left(H_{S R}\right.$ or $\left.L E_{S R}\right)$ for half hour $i$; and $\bar{x}$ is the average of the values of the independent variable.

\section{RESULTS AND DISCUSSION}

Table 1 summarizes the average meteorological conditions during the measurement period. There were only two slight precipitation events, less than 1.0 
$\mathrm{mm}$ each. Within the month prior to the experiment, there were only three significant precipitation events, amounting $24.4 \mathrm{~mm}$. Then, environmental conditions were relatively dry during the measurement period. Calibration period was slightly cooler than validation period. The warmer (31 July and 1 August) and the cooler (3 August) days were included in the validation period. Solar and net radiation were lower during the validation period. In fact, only 3 days (26, 27 and 29 July) were completely sunny, while the remaining 7 days were more or less overcast during parts of the day, mainly during afternoon and late evening. This is a typical situation in the Ebro River Basin during summer when a sultry weather during morning hours lead to the development of lightning storm clouds in the evening, frequently with little or not rain. Wind speeds were also greater during the validation period.

Figure 2 shows the time evolution of 30-min values of $H_{E C}$ and $H_{S R}$ for the 10 analyzed days for the longer time lag. $H_{S R}$ overestimated $H_{E C}$ for the three studied measurement heights. However, differences between $H_{S R}$ and $H_{E C}$ decreased as sensor height measurement decreased. Thus, for the longer time lag, $H_{S R}$ and $H_{E C}$ showed already a quite good agreement for $z=1.1$, being this agreement better for $z$ $=0.9 \mathrm{~m}$ (Figure 2). Similar behavior was observed for the shorter time lag but differences between $H_{E C}$ and $H_{S R}$ were higher. In any case, however, the most important differences between $H_{E C}$ and $H_{S R}$ were observed during unstable atmospheric conditions $(H>0)$, particularly when the peak $H$ values were recorded. Paw $U$ et al. (1995) already indicated that the results for the SR method were poorer for unstable atmospheric conditions because the temperature traces are generally smoother under stable atmospheric conditions $(H<0)$. Then, the $S R$ method is expected to perform better with smoother temperature traces. 
Figure 3 shows the index of agreement $(I A)$, root mean square error (RMSE) and systematic mean square error $\left(M S E_{s}\right)$ statistics obtained for the error analyses of $H_{S R}$ values for the calibration data subset. Errors increased as measurement height increased. The better results were obtained for $z=0.9 \mathrm{~m}$ for both time lags in terms of all three statistics. Likewise, results for longer time lags were clearly better than those obtained for the shorter time lags for the three measurement heights. Differences between results seen for $z=0.9 \mathrm{~m}$ and those seen for $z=1.1 \mathrm{~m}$ were smaller than differences between results seen for $z=1.1 \mathrm{~m}$ and those seen for $z=$ $1.4 \mathrm{~m}$. However, this was likely due to the fact that time lags used for $z=1.4 \mathrm{~m}$ were shorter than those used for the other two heights. This will be discussed later when presenting simple linear regression results. $I A$ values for the $z=0.9 \mathrm{~m}$ (longer time lag) case were quite high indicating a good agreement between $H_{E C}$ and $H_{S R}$ values. Subsequently, RMSE value for this case was the lower, only $27.7 \mathrm{~W} \mathrm{~m}^{-2}$, and all errors were practically random as $M S E_{s}$ value was only $10 \%$. This RMSE value was of similar magnitude of errors typically seen for eddy covariance systems (Paw U et al., 1995; Foken and Wichura, 1996; Spano et al., 1997). In terms of RE, errors for the $z=0.9 \mathrm{~m}$ (longer time lag) case were only $10 \%$, while they were about $41 \%$ for the worse case (shorter time lag, $z=1.4 \mathrm{~m}$ ).

Table 2 shows the results of the simple linear regressions between $H_{E C}$ and $H_{S R}$ (forced through the origin) for both time lags and the different measurement heights for the calibration data subset. The regression slopes represent the calibrated $\alpha$ values. All coefficients of determination $\left(R^{2}\right)$ of the regressions were higher than 0.8, except for the $z=1.4 \mathrm{~m}$ (shorter time lag) case, indicating that there was a high correlation between $H_{E C}$ and $H_{S R}$. 
The behavior of regression slopes, i.e. the calibrated $\alpha$ values, resembled that seen for the error analysis statistics. Thus, $\alpha$ values decreased as measurement height increased and higher $\alpha$ values were obtained for the longer time lag. For $z=$ $0.9 \mathrm{~m}$ (longer time lag), a $\alpha$ value of 1.0 was obtained. Similar results were reported by Snyder et al. (1996) and Duce et al. (1997) for surface renewal measurements taken over different plant canopies. Spano et al. (1997) performed surface renewal measurements over short-canopy crops such as grass, for four time lags $(0.25,0.50$, 0.75 and $1.00 \mathrm{~s}$ ) and also found that better results were obtained for longer time lags except for low measurement heights (0.3-0.4 m). Snyder et al. (1996) have argued that the mean wind shear is higher and the inverse ramp frequency is expected to be lower near the canopy height, implying that better estimates of $H$ should be expected for shorter time lags because the structure functions defined by Van Atta (1977) require the time lag $r$ be much smaller than the inverse ramp frequency $l+s$. At higher heights above ground, as in this research, the expected wind shear would be lower and so the inverse ramp frequency would be higher, implying that better estimates of $H$ should be expected for longer time lags (Snyder et al., 1996).

In this research, time lags for $z=1.4 \mathrm{~m}$ were lower than time lags for the other two measurement heights. So, the higher difference between results seen for that measurement height and those seen for $z=1.1$ and $z=0.9 \mathrm{~m}$ likely were due to that circumstance. In order to make a better assessment of those differences, some considerations must be done. In this research, $\alpha$ values were quite similar to those reported by Snyder et al. (1996) and Spano et al. (1997) for surface renewal measurements performed over grass and other short-canopy plants. Thus, Spano et al. (1997) found a $\alpha$ value of 0.92 for a time lag of $0.75 \mathrm{~s}$ and $z=0.9 \mathrm{~m}$, while in this 
research the $\alpha$ value for this case was practically 1.0 (Table 2). Spano et al. (1997) results indicate that the decrease of $\alpha$ values as a function of $z$ is fairly constant for different time lags, within the range of 0.3 to $1.2 \mathrm{~m}$ above ground. Additionally, Spano et al. (1997) results indicate a fairly constant change in $\alpha$ values as time lag increases for a given measurement height. Table 2 indicates that, for this research, ratios of $\alpha$ values for the longer and the shorter time lags were about 1.3, while ratios of $\alpha$ values for $z=1.1 \mathrm{~m}$ to those for $z=0.9 \mathrm{~m}$ were about 0.85 . Then, assuming that a similar ratio would have attained in this research if measurements for $z=1.4 \mathrm{~m}$ would have been taken for a time lag of $0.75 \mathrm{~s}$, a $\alpha$ value of about $0.70-0.75$ would have been obtained.

It is important to note that the relative change of $\alpha$ values between the different analyzed cases do not necessarily imply a similar relative change in accuracy of estimated $H_{S R}$ values. Thus, $R E$ values for the best two cases, $z=0.9$ and $1.1 \mathrm{~m}$ (longer time lag) were 10 and $12 \%$, respectively, a decrease in accuracy of only $2 \%$, although $\alpha$ values disagreed by about $15 \%$. For short canopies, a $\alpha$ value of about 1.0 has been postulated when measurements are taken well above the canopy. Assumptions are that heating (cooling) of the mean renewal parcel volume is uniform with height, and heat flux occurs instantaneously and adiabatically during the sweep and ejection phase (Snyder et al., 1996). These assumptions likely do not hold strictly speaking as indicated by $\alpha$ values departing from 1.0. Some authors have pointed out the existence of small-scale vertical advection of heated air, circumstance that would explain that departure (Gao et al., 1989; Paw U et al., 1992). However, within some range of heights above canopy top, the departure from $\alpha=1.0$ 
may not be critical as indicated by the small change in $H_{S R}$ uncertainty observed in this study for measurements taken at 0.9 and $1.1 \mathrm{~m}$ above ground. As measurement height increases, temperature readings become gradually more affected by entrainment with air aloft and uncertainty increases (Spano et al., 1997).

Figure 4 shows the index of agreement $(I A)$ and systematic mean square error $\left(M S E_{S}\right)$ statistics computed for the error analyses of $L E_{S R}$ values for the calibration data subset. The behavior of those statistics as function of time lag and measurement height was quite similar to that observed in the case of $H$. Nevertheless, IA values were slightly higher and $M S E_{s}$ values were noticeably lower than those for $\mathrm{H}$, indicating than errors for $L E_{S R}$ were mostly random for all cases. The $z=0.9 \mathrm{~m}$ (longer time lag) case was again the best as shown by a very high $I A$ value indicating the good agreement between $L E_{S R}$ and $L E_{E C}$ data sets. For $L E$, however, $M S E_{s}$ was lower for the case of $z=1.1 \mathrm{~m}$ instead. As $L E_{S R}$ and $L E_{E C}$ values were obtained from solving the energy balance equation, RMSE values were the same than those obtained for $H$. However, $R E$ values for $L E$ were slightly lower because of the highest range of $L E_{E C}$ values. Thus, $R E$ value for the $z=0.9 \mathrm{~m}$ (longer time lag) case was less than $9.0 \%$.

Figure 5 shows the IA, RMSE and $M S E_{s}$ statistics computed for the error analyses of $H_{S R}$ values for the validation data subset. Similarly, Figure 6 shows the $I A$ and $M S E_{s}$ statistics computed for error analyses of $L E_{S R}$ values for the validation data subset. For all cases, differences between statistics were quite small although the case for $z=0.9 \mathrm{~m}$ (longer time leg) was slightly better. All statistics values were quite similar to those seen for the $z=0.9 \mathrm{~m}$ (longer time lag) case for the calibration data subset. These results show that the calibration of $H_{S R}$ was adequate for all 
cases and then that it is possible to measure $H_{S R}$ for different time lags and measurement heights as long as a calibration is performed.

Likewise, it was reasonable to think that the discussed departure from $\alpha=1.0$ could be affected by different meteorological conditions as these conditions would alter the mean surface renewal parcel volume. In this research, the calibration factors obtained have shown to be valid under somewhat different meteorological conditions for which they were obtained (Table 1). However, these meteorological conditions were not sharply different and so conclusive results can not be obtained. Further research under more distinct meteorological and environmental conditions would be required in order to have a better assessment of the stability of the calibration factor as a function of time.

Nevertheless, results from this research indicate that the use of the surface renewal method could be adequate to estimate long-term evaporation from the playa and margins of the Gallocanta lagoon. Reasons are its relative accuracy and its simplicity and low cost compared to other accurate micrometeorological methods requiring more expensive and sophisticated instrumentation. Then, if long-term evapotranspiration measurements are required at remote sites and maintenance and other costs must be kept low, surface renewal might be an adequate alternative to the eddy covariance or other micrometeorological methods. It must be recognized, though, that, besides the problems already discussed, the estimation of $H_{S R}$ for a given time period is not always possible if the estimated mean inverse frequency ramp $1+s$ is lower than 5 times the time lag $r$. In this research, this problem occurred for about 5 to $7 \%$ of all 30-min analyzed periods, generally during nighttime hours 
when latent heat flux is close to 0 . Then, this problem should not be of a serious concern, in general terms.

\section{CONCLUSIONS}

A high correlation was found between surface renewal sensible heat flux $\left(H_{S R}\right)$ and eddy covariance sensible heat flux $\left(H_{E C}\right)$ values during the calibration period (25 July to 30 July 2000) of this research. Almost all coefficients of determination were higher than 0.8 regardless of measurement height and time lag. The regression slopes showed that the calibration factor $\alpha$ decreases as measurement height increases. Similarly, $\alpha$ values for longer time lag were higher. Thus, $H_{S R}$ accuracy, as indicated by the computed IA, RMSE and $M S E_{s}$ statistics, was highly improved as measurement height decreased and time lag increased. The best results were obtained for the $z=0.9 \mathrm{~m}$ (longer time lag) case. For this case, uncertainty was about $10 \%$, according to the computed $R E$ statistics, and was mostly at random.

During the calibration period, estimates of $L E_{S R}$ showed similar accuracy than $H_{S R}$ estimates as a function of measurement height and time lag, although that accuracy was mostly at random for all cases. The uncertainty of $L E_{S R}$ values was less than $9 \%$ for the $z=0.9 \mathrm{~m}$ (longer time lag) case.

When the obtained $\alpha$ calibration factors were applied for the validation data subsets, the agreement between $H_{S R}$ and $H_{E C}$ values and between $L E_{S R}$ and $L E_{E C}$ values was high for all cases regardless of time lag and measurement height. For the validation data subset, accuracy of $H_{S R}$ and $L E_{S R}$ was quite similar to that seen for the best case for the calibration data subset. Nevertheless, results for the $z=0.9 \mathrm{~m}$ (longer time lag) were still slightly better. It can be concluded then that the calibration 
factors can be applied under somewhat different meteorological conditions. Further research is needed relative to the calibration factor time variability under more sharply distinct meteorological conditions. Under the conditions of this research, the most adequate time lag and measurement height in order to improve $L E_{S R}$ estimates were $0.75 \mathrm{~s}$ and $0.9 \mathrm{~m}$, respectively.

\section{ACKNOWLEDGMENTS}

This research was funded by the Confederación Hidrográfica del Ebro (Spanish Ministry of Environment) and EPTISA, an Engineering Services private company. Authors thank Dr. Ramón Aragüés for his instrumentation and labor facilities, Dr. R. L. Snyder for his assistance in datalogger programming, Miguel Ángel García-Vera for his collaboration for research planning, and Jesús Gaudó and Miguel Izquierdo for his valuable work during weather station installation. Thanks are also due to the Environmental Protection Agents of the Gallocanta basin for the periodic surveillance of the weather station. 


\section{REFERENCES}

Allison, G.B., Barnes, C.J. 1985. Estimation of evaporation from the normally "dry" Lake Frome in South Australia. Journal of Hydrology. 78: 229-242.

ASCE. 1996. Hydrology Handbook. ASCE Manuals and Reports on Engineering Practice No. 28. American Society of Civil Engineerings (ASCE), New York. xxxix $+784 \mathrm{p}$.

Chen, W., Novak, M.D., Black, A., Lee, X. 1997. Coherent eddies and temperature structure functions for three contrasting surfaces. Part I: ramp model with finite microfront time. Boundary-Layer Meteorology. 84: 99-123.

Culf, A.D., Allen, S.J., Gash, J.H.C., Lloyd, C.R., Wallace, J.S. 1993. Energy and water budgets of an area of patterned woodland in the Sahel. Agricultural and Forest Meteorology. 66 (1-2): 65-80.

De Bruin, H.A.R., Kohsiek, W., Vandenhurk, B.J.J.M. 1993. A verification of some methods to determine the fluxes of momentum, sensible heat, and water vapor using standard deviation and structure parameter of scalar meteorological quantities. Boundary-Layer Meteorology. 63 (3): 231-257.

Duce, P., Spano, D., Snyder, R.L., Paw U, K.T. 1997. Surface renewal estimates of evapotranspiration. Short canopies. Proceedings of the $2^{\text {nd }}$ International Symposium on Irrigation of Horticultural Crops. K.S. Chartzoulakis (ed.). Acta Horticulture. 449 (vol. 1): 57-62.

Foken, T., Wichura, B. 1996. Tools for quality assessment of surface-based flux measurements. Agricultural and Forest Meteorology. 78: 83-105. 
Gao, W., Shaw, R.H., Paw U, K.T. 1989. Observation of organized structure in turbulent flow within and above a forest canopy. Boundary-Layer Meteorology. 47: 349-377.

Goutorbe, J.P., Lebel, T., Dolman, A.J., Gash, J.H.C., Kabat, P., Kerr, Y.H., Monteny, B., Prince, S.D., Stricker, J.N.M., Tinga, A., Wallace, J.S. 1997. An overview of HAPEX-Sahel: a study in climate and desertification. Journal of Hydrology. 188189 (1-4): 4-17.

Kristensen, L., Mann, J., Oncley, S.P., Wyngaard, J.C. 1997. How close is close enough when measuring scalar fluxes with displaced sensors?. Journal of Atmospheric and Oceanic Technology. 14: 814-821.

Lapitan, R.L., Parton, W.J. 1996. Seasonal variabilities in the distribution of the microclimatic factors and evapotranspiration in a shortgrass steppe. Agricultural and Forest Meteorology. 79 (1-2): 113-130.

Jacobs, A.F.G., Verhoef, A. 1997. Soil evaporation from sparse natural vegetation estimated from Sherwood numbers. Journal of Hydrology. 188-189 (1-4): 443-452.

Malek, E., Bingham, G.E., McCurdy, G.D. 1990. Evapotranspiration from the margin and moist playa of a closed desert valley. Journal of Hydrology. 120: 15-34.

Malek, E., Bingham, G.E., Or, D., McCurdy, G. 1997. Annual mesoscale study of water balance in a Great Basin heterogeneous desert valley. Journal of Hydrology. 191 (1-4): 223-244.

Monteith, J.L., Unsworth, M.H. 1990. Principles of environmental physics. Edward Arnold, London New York Melbourne Auckland. xii + 291 pp. 
Paw U, K.T., Brunet, Y. 1991. A surface renewal measure of sensible heat flux density. $20^{\text {th }}$ Conference on Agriculture and Forest Meteorology. September 1013, 1991. Salt Lake City, Utah. 52-53. American Meteorological Society.

Paw U, K.T., Brunet, Y., Collineau, S., Shaw, R.H., Maitani, T., Qiu, J., Hipps, L. 1992. On coherent structures in turbulence above and within agricultural plant canopies. Agricultural and Forest Meteorology. 61: 55-68.

Paw U, K.T., Qiu, J., Su, H.B., Watanabe, T., Brunet, Y. 1995. Surface renewal analysis: a new method to obtain scalar fluxes without velocity data. Agricultural and Forest Meteorology. 74: 119-137.

Qiu, G.Y., Yano, T., Momii, K. 1999. An improved methodology to measure evaporation from bare soil based on comparison of surface temperature with a dry soil surface. Journal of Hydrology. 210 (1-4): 93-105.

Shaw, R.H., Paw U, K.T., Gao, W. 1989. Detection of temperature ramps and flow structures at a deciduous forest site. Agricultural and Forest Meteorology. 47: 123138.

Snyder, R.L., Spano, D., Paw U, K.T. 1996. Surface renewal analysis for sensible and latent heat flux density. Boundary-Layer Meteorology. 77: 249-266.

Spano, D., Snyder, R.L., Duce, P., Paw U, K.T. 1997. Surface renewal analysis for sensible heat flux density using structure functions. Agricultural and Forest Meteorology. 86: 259-271.

Spano, D., Snyder, R.L., Duce, P., Paw U, K.T. 2000. Estimating sensible and latent heat flux densities from grapevine canopies using surface renewal. Agricultural and Forest Meteorology. 104 (3): 171-183. 
Van Atta, C.W. 1977. Effect of coherent structures on structure functions of temperature in the atmospheric boundary layer. Archives of Mechanics. 29 (1): $161-171$.

Villalobos, F.J. 1997. Correction of eddy covariance water vapor flux using additional measurements of temperature. Agricultural and Forest Meteorology. 88: 77-83.

Willmott, C.J. 1982. Some comments on the evaluation of model performance. Bulletin American Meteorological Society. 63 (11): 1309-1313.

Wythers, K.R., Lauenroth, W.K., Paruelo, J.M. 1999. Bare-soil evaporation under semiarid field conditions. Soil Science Society of America Journal. 63 (5): 13411349. 
Table 1. Average meteorological conditions during each single day of the experiment as well as the calibration and validation periods. In this work, a single day ran from 12:00 GMT to 11:30 GMT next day. $P R$, daily precipitation; $T m$, mean daily air temperature; $T x$, maximum air temperature; $T n$, minimum air temperature; $R H$, mean daily air relative humidity; $R S$, mean daily incoming global short-wave solar radiation; $R N$, mean daily net radiation; $G$, mean daily soil heat flux; $W S$, mean daily wind speed.

\begin{tabular}{|c|c|c|c|c|c|c|c|c|c|}
\hline Date & $\begin{array}{c}\mathrm{PR} \\
(\mathrm{mm})\end{array}$ & $\begin{array}{c}\mathrm{Tm} \\
\left({ }^{\circ} \mathrm{C}\right)\end{array}$ & $\begin{array}{c}\mathrm{TX} \\
\left({ }^{\circ} \mathrm{C}\right)\end{array}$ & $\begin{array}{c}\mathrm{TN} \\
\left({ }^{\circ} \mathrm{C}\right)\end{array}$ & $\begin{array}{c}R H \\
(\%)\end{array}$ & $\begin{array}{c}R S \\
\left(\mathrm{~W} \mathrm{~m}^{-2}\right)\end{array}$ & $\begin{array}{c}R N \\
\left(\mathrm{~W} \mathrm{~m}^{-2}\right)\end{array}$ & $\begin{array}{c}G \\
\left(\mathrm{~W} \mathrm{~m}^{-2}\right)\end{array}$ & $\begin{array}{c}W S \\
\left(\mathrm{~m} \mathrm{~s}^{-1}\right)\end{array}$ \\
\hline 25 July & 0.0 & 19.0 & 26.3 & 9.6 & 51.7 & 318.8 & 148.2 & 3.3 & 3.6 \\
\hline 26 July & 0.0 & 21.7 & 29.1 & 12.5 & 42.1 & 333.6 & 147.2 & 6.7 & 1.9 \\
\hline 27 July & 0.0 & 22.4 & 31.8 & 12.3 & 46.1 & 326.8 & 148.1 & 4.3 & 2.9 \\
\hline 28 July & 0.0 & 19.3 & 26.4 & 11.0 & 50.4 & 316.3 & 141.1 & 2.2 & 2.9 \\
\hline 29 July & 0.0 & 21.1 & 28.6 & 12.2 & 46.5 & 320.5 & 145.7 & 7.2 & 2.8 \\
\hline 30 July & 0.0 & 24.9 & 31.6 & 16.1 & 51.4 & 296.1 & 134.4 & 10.1 & 2.5 \\
\hline 31 July & 0.8 & 25.4 & 34.5 & 18.1 & 48.5 & 255.4 & 116.7 & 3.2 & 2.7 \\
\hline 01 Aug & 0.8 & 25.0 & 35.5 & 18.1 & 46.6 & 238.2 & 111.9 & 1.6 & 3.9 \\
\hline 02 Aug & 0.0 & 19.6 & 29.7 & 11.3 & 62.6 & 299.4 & 135.9 & -2.7 & 4.5 \\
\hline 03 Aug & 0.0 & 14.4 & 21.4 & 6.6 & 64.1 & 222.6 & 92.4 & -13.5 & 3.9 \\
\hline $\begin{array}{c}\text { Calibration } \\
\text { period }\end{array}$ & 0.0 & 20.7 & 31.8 & 9.6 & 47.4 & 323.2 & 146.1 & 4.7 & 2.8 \\
\hline $\begin{array}{c}\text { Validation } \\
\text { period }\end{array}$ & 1.6 & 21.9 & 35.5 & 6.6 & 54.5 & 262.7 & 118.5 & -0.1 & 3.5 \\
\hline
\end{tabular}


Table 2. Simple linear regressions between $H_{E C}$ (dependent variable) and $H_{S R}$ (independent variable) computed for the calibration data subset $(n=215)$, for different time lags and measurement heights.

\begin{tabular}{|c|c|c|c|c|c|c|}
\hline \multirow[b]{3}{*}{ Time lag } & \multicolumn{3}{|c|}{ Regression slopes } & \multicolumn{3}{|c|}{ Coefficients of determination } \\
\hline & \multicolumn{3}{|c|}{ Measurement height (m) } & \multicolumn{3}{|c|}{ Measurement height (m) } \\
\hline & 0.9 & 1.1 & 1.4 & 0.9 & 1.1 & 1.4 \\
\hline Shorter $^{2}$ & 0.778 & 0.657 & 0.453 & 0.873 & 0.863 & 0.786 \\
\hline Longer $^{3}$ & $0.999^{1}$ & 0.851 & 0.583 & 0.871 & 0.854 & 0.811 \\
\hline
\end{tabular}

${ }^{1}$ No significantly different than 1 (level of significance, 0.95).

${ }^{2} 0.25 \mathrm{~s}$ for $z=1.4 \mathrm{~m}, 0.375 \mathrm{~s}$ for $z=1.1$ and $0.9 \mathrm{~m}$.

${ }^{3} 0.50 \mathrm{~s}$ for $z=1.4 \mathrm{~m}, 0.75 \mathrm{~s}$ for $z=1.1$ and $0.9 \mathrm{~m}$. 


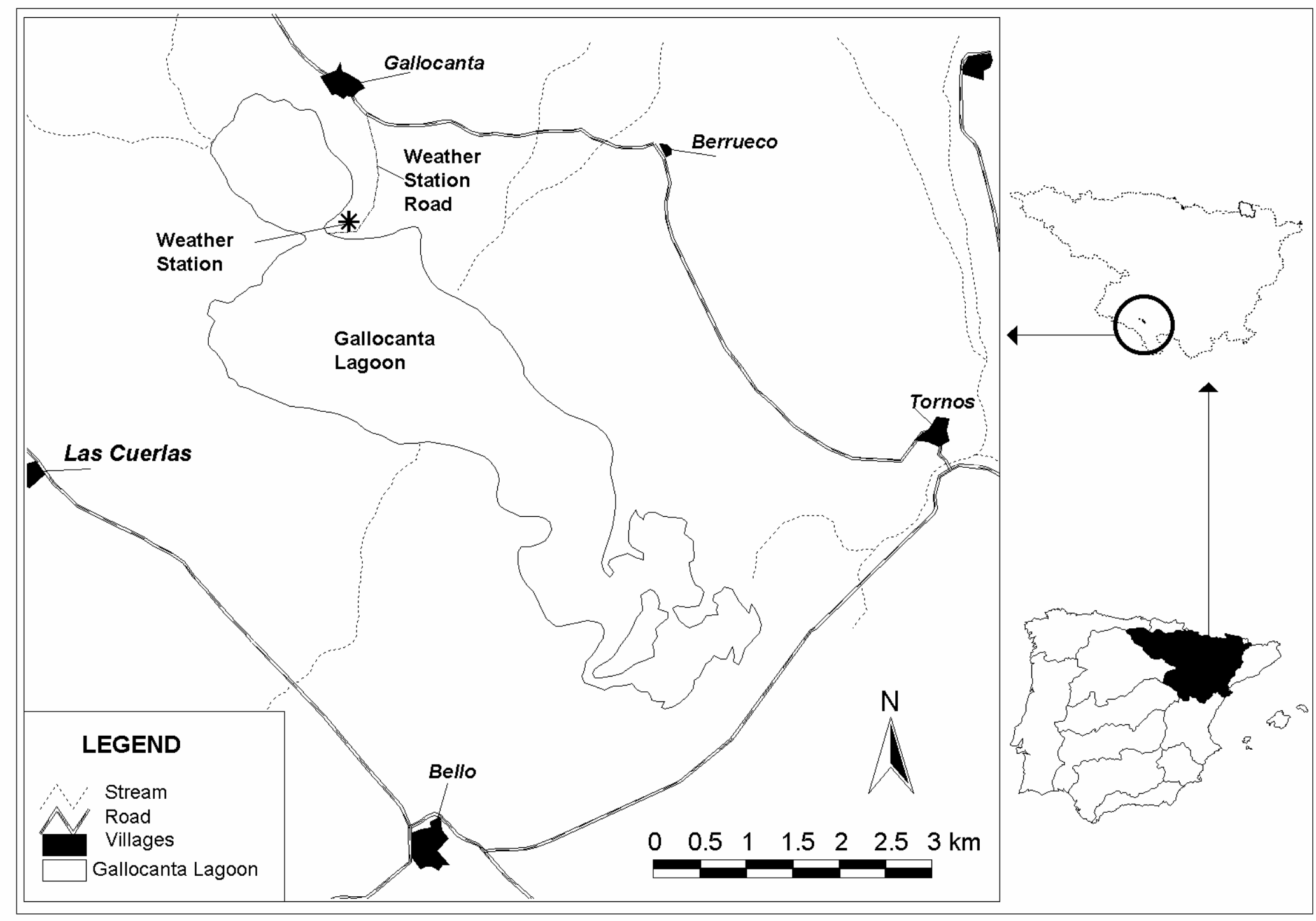

Figure 1. Location of the Gallocanta lagoon and the weather station site. 

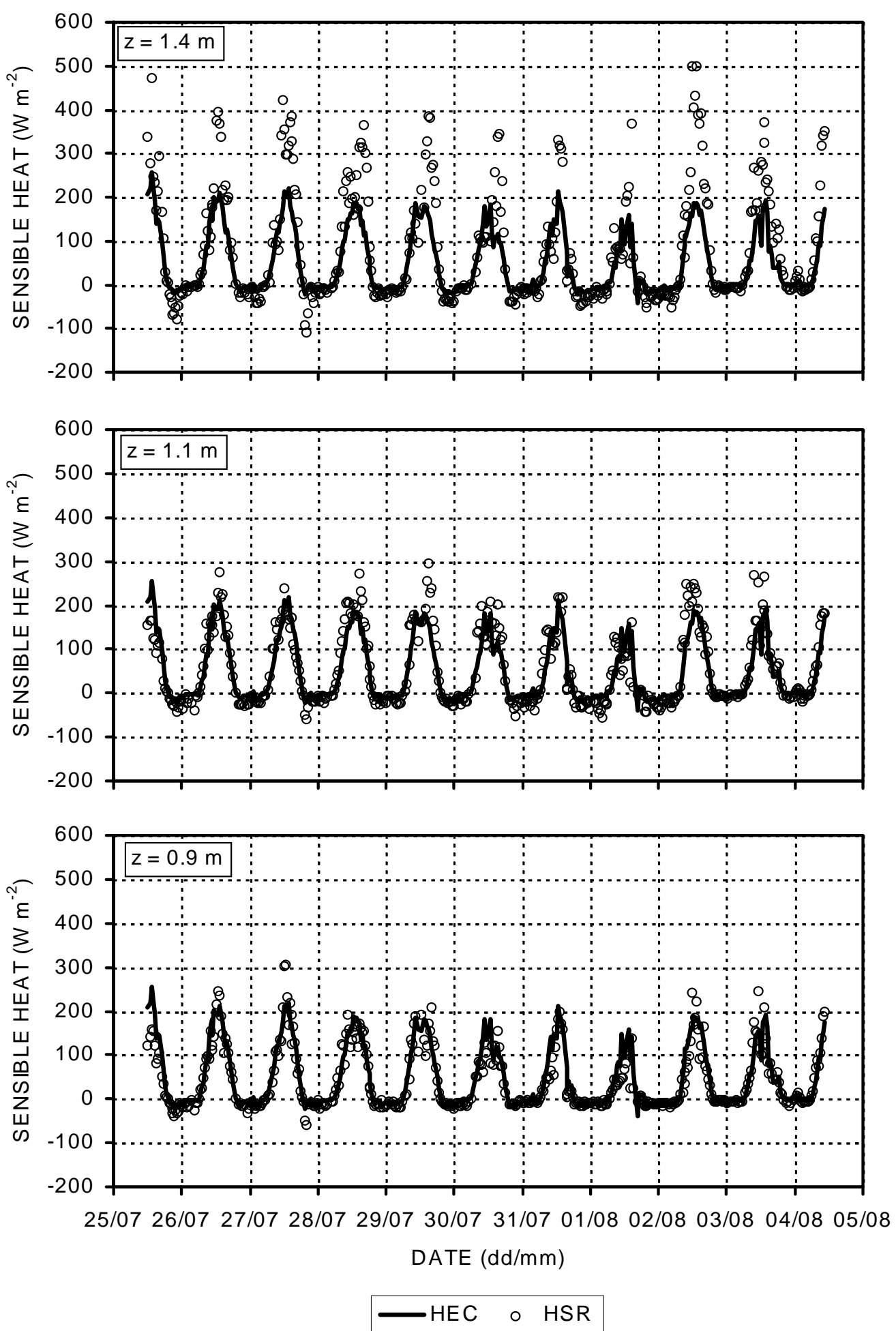

Figure 2. Measured (eddy covariance, $H_{E C}$ ) and estimated (surface renewal, $H_{S R}$ ) sensible heat flux versus time, for the longer time lag and three measurement heights $(r=0.50 \mathrm{~s}$ for $z=1.4 \mathrm{~m} ; r=0.75 \mathrm{~s}$ for $z=1.1$ and $0.9 \mathrm{~m})$. 

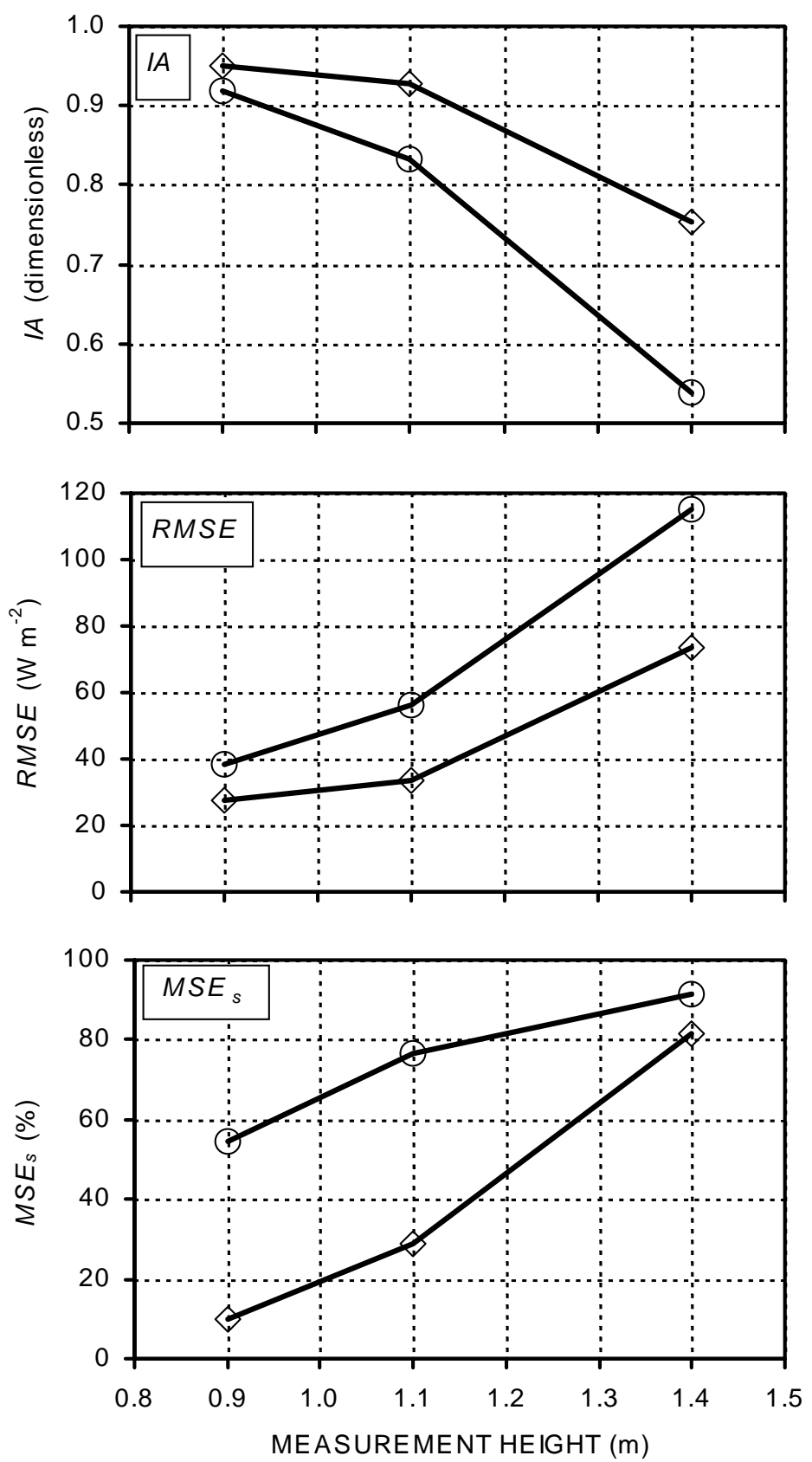

$\neg$ Longer time lag $\multimap$ Shorter time lag

Figure 3. Statistics of the error analysis of $H_{S R}$ values obtained for the calibration data subset $(n=215)$ as a function of measurement height and time lag. IA, index of agreement. RMSE, root mean square error. $M S E_{S}$, systematic mean square error. Longer time lags: $0.50 \mathrm{~s}$ for $z=1.4 \mathrm{~m}, 0.75 \mathrm{~s}$ for $z=1.1$ and $0.9 \mathrm{~m}$. Shorter time lags: $0.25 \mathrm{~s}$ for $z=1.4 \mathrm{~m}, 0.375 \mathrm{~s}$ for $z=1.1$ and $0.9 \mathrm{~m}$. 

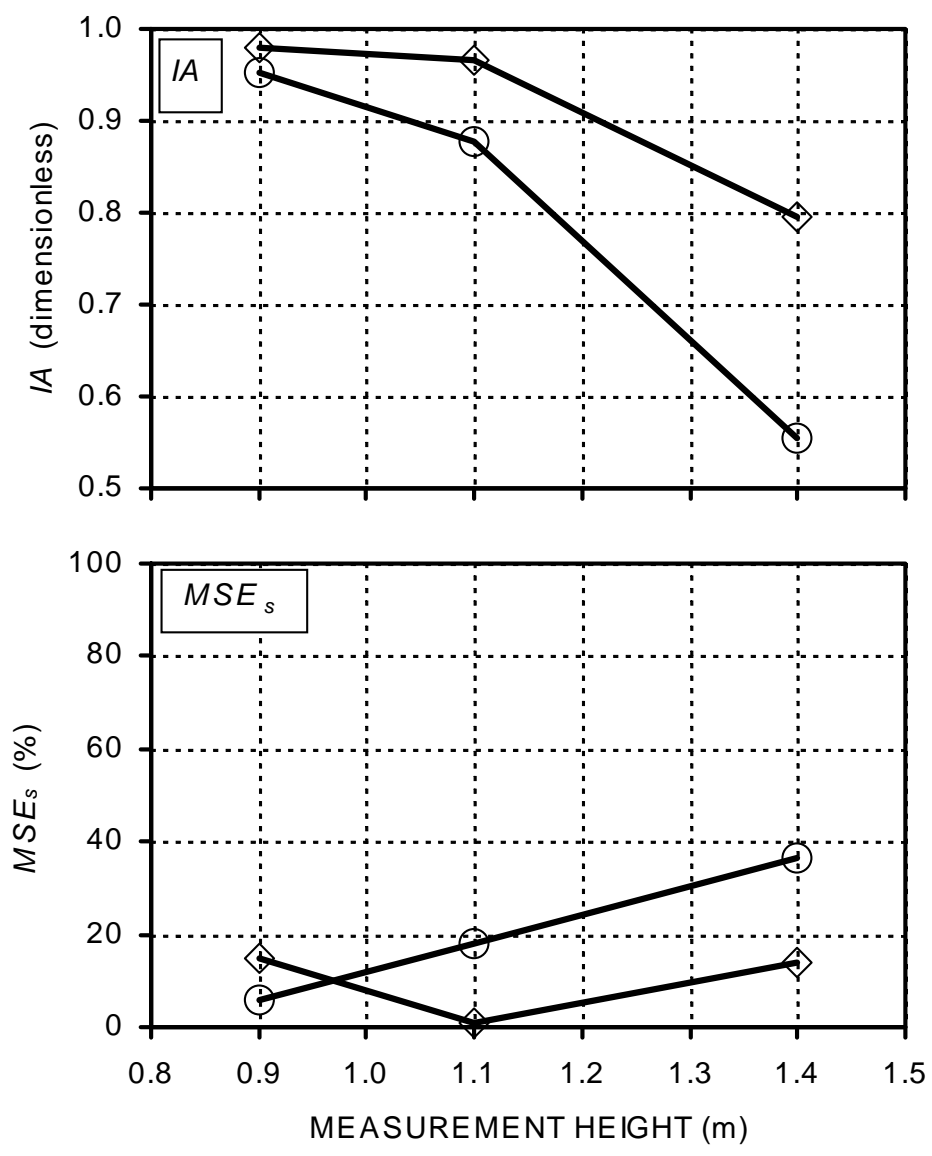

$\checkmark$ Longer time lag $\neg$ Shorter time lag

Figure 4. Statistics of the error analysis of $L E_{S R}$ values obtained for the calibration data subset $(n=215)$ as a function of measurement height and time lag. IA, index of agreement. $M S E_{s}$, systematic mean square error. Longer time lags: $0.50 \mathrm{~s}$ for $z=1.4$ $\mathrm{m}, 0.75 \mathrm{~s}$ for $z=1.1$ and $0.9 \mathrm{~m}$. Shorter time lags: $0.25 \mathrm{~s}$ for $z=1.4 \mathrm{~m}, 0.375 \mathrm{~s}$ for $z=$ 1.1 and $0.9 \mathrm{~m}$. 

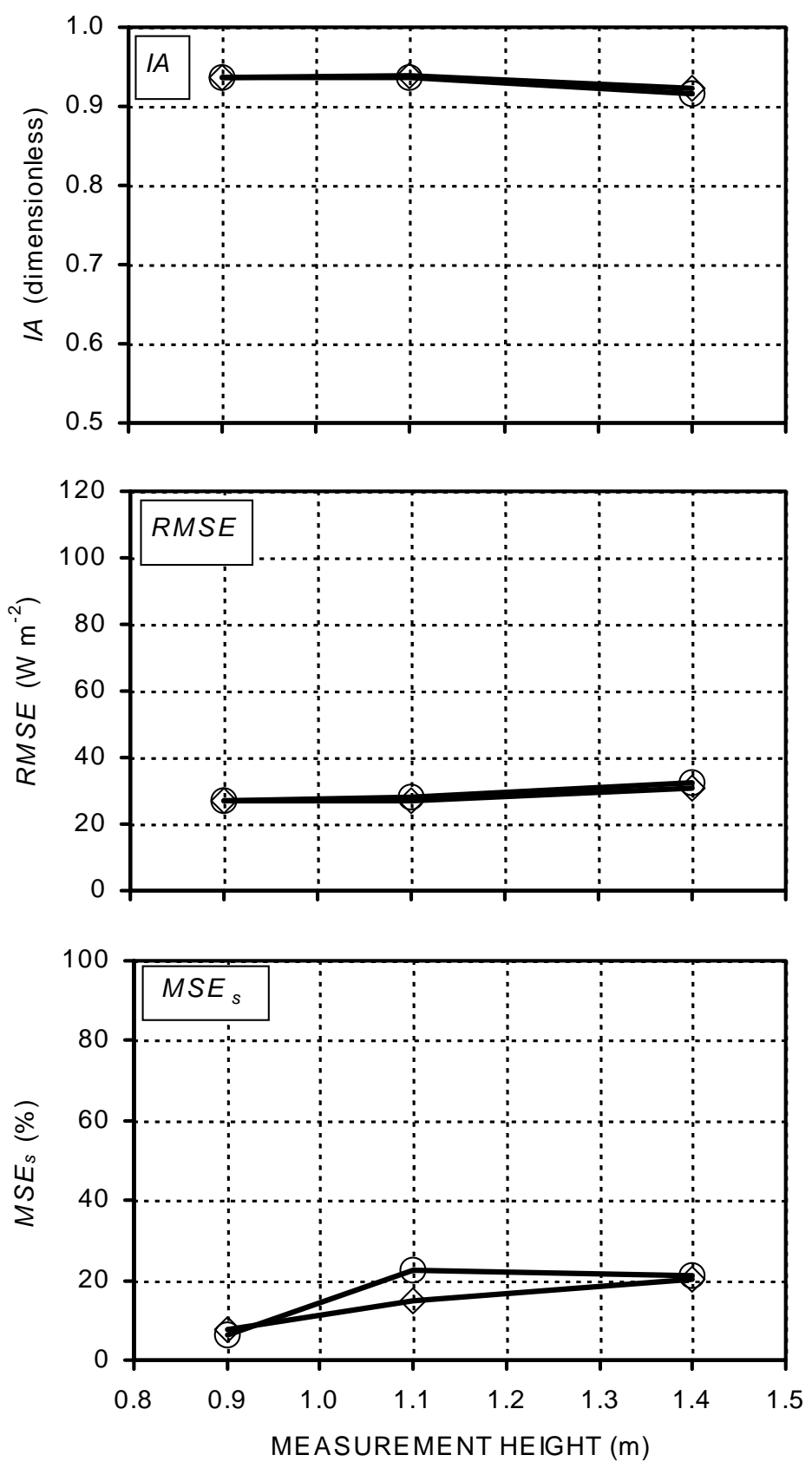

$\checkmark$ Longer time lag $\prec$ Shorter time lag

Figure 5. Statistics of the error analysis of $H_{S R}$ values obtained for the validation data subset $(n=219)$ as a function of measurement height and time lag. IA, index of agreement. RMSE, root mean square error. $M S E_{S}$, systematic mean square error. Longer time lags: $0.50 \mathrm{~s}$ for $z=1.4 \mathrm{~m}, 0.75 \mathrm{~s}$ for $z=1.1$ and $0.9 \mathrm{~m}$. Shorter time lags: $0.25 \mathrm{~s}$ for $z=1.4 \mathrm{~m}, 0.375 \mathrm{~s}$ for $z=1.1$ and $0.9 \mathrm{~m}$. 

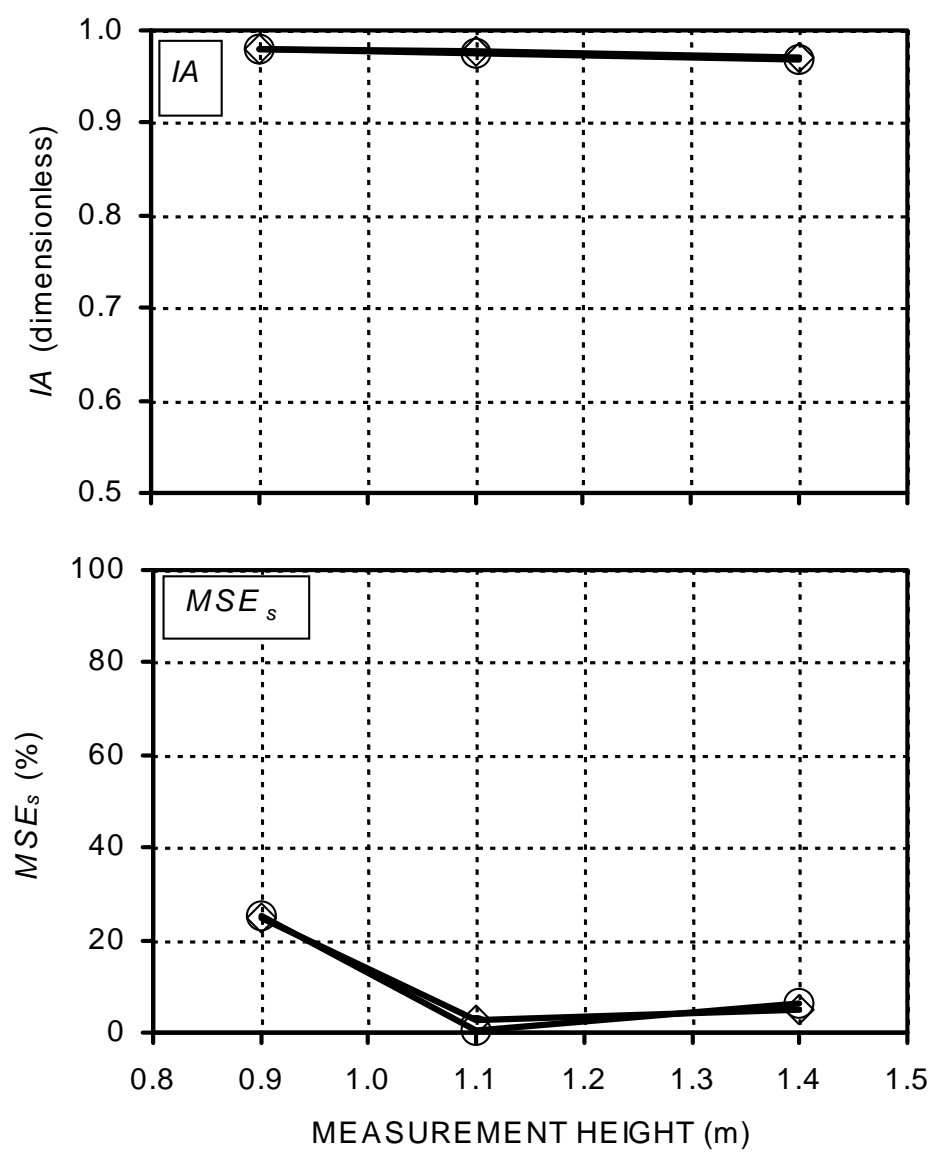

$\curvearrowright$ Longer time lag $\curvearrowright$ Shorter time lag

Figure 6. Statistics of the error analysis of $L E_{S R}$ values obtained for the validation data subset $(n=219)$ as a function of measurement height and time lag. $I A$, index of agreement. $M S E_{s}$, systematic mean square error. Longer time lags: $0.50 \mathrm{~s}$ for $z=1.4$ $\mathrm{m}, 0.75 \mathrm{~s}$ for $z=1.1$ and $0.9 \mathrm{~m}$. Shorter time lags: $0.25 \mathrm{~s}$ for $z=1.4 \mathrm{~m}, 0.375 \mathrm{~s}$ for $z=$ 1.1 and $0.9 \mathrm{~m}$. 